\title{
Genome-Wide Identification of the Dehydrin Genes in the Cucurbitaceae Species
}

\author{
Sang-Choon Lee ${ }^{1}$, Won-Kyung Lee ${ }^{1}$, Asjad $\mathrm{Ali}^{2}$, Manu Kumar ${ }^{3}$, Tae-Jin Yang ${ }^{1}$, Kihwan Song ${ }^{4}$ * \\ ${ }^{1}$ Department of Plant Science, Plant Genomics and Breeding Institute, and Research Institute of Agriculture and Life Sciences, \\ College of Agriculture and Life Sciences, Seoul National University, Seoul 08826, Korea \\ ${ }^{2}$ Southern Cross Plant Science, Southern Cross University, Lismore, NSW 2480, Australia \\ ${ }^{3}$ Department of Life Science, Sogang University, Seoul 04107, Korea \\ ${ }^{4}$ Department of Bioresources Engineering, College of Life Sciences, Sejong University, Seoul 05006, Korea
}

\begin{abstract}
Dehydrins (DHNs) are hydrophilic proteins with conserved lysine-rich K-segment, which belong to Group II of the late embryogenesis abundant (LEA) protein family. DHNs are considered as molecular chaperons playing important roles in abiotic stress tolerance. In this study, $D H N$ genes were identified through genome-wide searches in five Cucurbitaceae species, including cucumber, wild cucumber, melon, watermelon, and bitter gourd. Three to five $D H N$ genes were found in each of the five species, which were further divided into several protein architecture types based on the presence and order of the major conserved motifs such as K-, Y-, and S-segments. In silico expression profiling using RNA-Seq data revealed high expression of $\mathrm{SK}_{3}$-type $D H N$ gene and low expression of other type $D H N$ genes in cucumber and melon. In silico promoter analysis identified a number of cis-acting element-like sequences related to abiotic stress-response such as DRE and ABRE in 2-kb putative promoter sequences. $D H N$ genes identified in this study will be valuable for understanding the stress response mechanism as well as assisting molecular breeding in Cucurbitaceae crops.
\end{abstract}

Keywords Dehydrin, DHN, Cucumber, Cucurbitaceae

\section{INTRODUCTION}

Dehydrins (DHNs) are hydrophilic proteins with conserved K-segment and belong to Group II of the late embryogenesis abundant (LEA) protein family. $\mathrm{K}$-segment is a lysine-rich amino acid sequence (EKKGIMDKIKEKLPG and similar sequences), which is highly conserved in most DHNs. In addition, Y-segment [(V/T)D(E/Q)YGNP] and S-segment (5 to 7 Ser residues) are often found in DHNs. DHNs can be classified into five architecture types, such as $K_{n}, S_{n}, K_{n} S, Y_{n} K_{n}$, and $Y_{n} S_{n}$, according to the presence and order of K-, S- and Y-segments within protein sequence (Close 1996; Graether and Boddington 2014). DHNs are found in various subcellular locations such as cytoplasm, nucleus, mitochondria, chloroplast, vacuole and in the vicinity of the plasma membrane (Graether and Boddington 2014).

DHNs are considered as molecular chaperones that protect various cellular components under stress conditions, such as proteins, enzymes, nucleic acids and membranes (Hara 2010; Hanin et al. 2011). Furthermore, the expressions of many $D H N$ genes have shown a positive correlation with plant stress tolerance under abiotic stress conditions (Bravo et al. 2003; Hara et al. 2003; Houde et al. 2004; Brini et al. 2007; Graether and Boddington 2014; Kumar et al. 2014).

Until now, a number of $D H N$ genes have been identified in many plant species. (Zolotarov and Strömvik 2015).

Received October 11, 2017; Revised November 1, 2017; Accepted November 1, 2017; Published December 1, 2017

*Corresponding author Tae-Jin Yang, tjyang@snu.ac.kr, Tel: +82-2-880-4547, Fax: +82-2-873-2056

*Comesponding author Kihwan Song, khsong@sejong.ac.kr, Tel: +82-2-3408-2905, Fax: +82-2-3408-4318 
Among those, many were also identified to encode $\mathrm{RAB}$ (responsive to abscisic acid) and COR (cold-regulated) proteins (Kusano et al. 1992; Welin et al. 1995; Danyluk et al. 1998; Nylander et al. 2001). For example, 10 and eight $D H N$ genes were identified in Arabidopsis thaliana and Oryza sativa ssp. japonica, respectively, and their stress responsiveness was studied (Hundertmark and Hincha 2008; Verma et al. 2017). Although a number of studies have identified $D H N$ genes and tried to reveal their biological roles, the precise function of the proteins still remains unclear.

The Cucurbitaceae family is composed of about 120 genera and more than 800 species, including many economically important crops such as cucumber, melon and watermelon (Lu and Jeffrey 2011). So far, nuclear genomes of seven crop species in the Cucurbitaceae family have been sequenced. Among those, Cucumis sativus var. sativus (cucumber) is an economically important crop and the genomes of three cucumber cultivars have been sequenced (Huang et al. 2009; Cavagnaro et al. 2010; Wóycicki et al. 2011). In addition, a wild cucumber species, Cucumis sativus var. hardwickii, was also analyzed for its genome sequencing (Qi et al. 2013). Similarly, genomes of some other important crops of the Cucurbitaceae family such as Cucumis melo (melon), Citrullus lanatus (watermelon) and Momordica charantia (bitter gourd) have also been sequenced (Garcia-Mas et al. 2012; Guo et al. 2013; Urasaki et al. 2016). Recently, genome sequences of bottle gourd (Lagenaria siceraria) and pumpkin species (Cucurbita maxima and Cucurbita moschata) became available (Wu et al. 2017; http://cucurbitgenomics.org/).

Like other crops, the growth of Cucurbitaceae crops is also adversely affected by abiotic stresses, which results in severe yield loss. In case of cucumber, its growth is inhibited at a temperature higher than $35^{\circ} \mathrm{C}$ and lower than $12^{\circ} \mathrm{C}$ as well as under stress conditions such as low humidity and high salt concentration (RDA 2013; Ali et al. 2014a, 2014b). Many studies have been carried out to understand the physiological and molecular mechanisms of stress response and to enhance abiotic stress-tolerance in Cucurbitaceae crops. However, the studies are still in their early phases for molecular breeding in the crops.

Although several $D H N$ genes were identified as a part of
LEA protein study in cucumber, melon and watermelon (Celik Altunoglu et al. 2016; Celik Altunoglu et al. 2017), no comprehensive study on the $D H N$ gene has been carried out in Cucurbitaceae species. On this account, this study identified and compared $D H N$ genes through genome-wide searches in five Cucurbitaceae species. The DHN genes studied here can be used in understanding the stress response mechanism and developing abiotic stress-tolerant crops in the Cucurbitaceae family.

\section{MATERIALS AND METHODS}

\section{Identification of $\mathrm{DHN}$ genes}

Eight gene sets of cucumber cultivars, wild cucumber, melon and watermelon cultivars were retrieved from genome database of respective plant. Gene set of bitter gourd was kindly provided by Prof. Hideo Matsumura in Shinshu University, Japan. Deduced protein sequences of 10 genomes including Arabidopsis and rice genomes (as references) were used to investigate $D H N$ genes (Table 1). InterProScan software (ver. 5.16-55.0 or 5.18-57.0, https:// www.ebi.ac.uk/interpro/, Jones et al. 2014) was employed to identify DHN protein sequences, with default parameters. Protein sequences with K-segment (InterPro IDs IPR000167 and IPR030513) were selected as DHNs and used for further study.

\section{Investigation of DHN architectures and subcellular location}

Protein architectures of selected $D H N$ genes were further divided on the basis of presence and order of conserved motifs such as K-, Y-, and S-segments (Close 1996; Graether and Boddington 2014). To find amino acid sequence conserved in DHNs, in-house Python script was used with conserved amino acid sequence information of three segments, such as "[KR][LIMV][KMR][DE][KQ] [LFI] …" for K-segment, "S[4,10]" for S-segment, and "DE.GNP" for Y-segment and then the retrieved conserved sequences were manually confirmed. Subcellular location of DHNs was predicted using three different web tools, PSORT (https://wolfpsort.hgc.jp/), TargetP 1.1 (http://www. cbs.dtu.dk/services/TargetP/), and ProtComp 9.0 (http:// 
Table 1. Gene sets of Cucurbitaceae species, A. thaliana, and rice used in this study.

\begin{tabular}{|c|c|c|c|c|}
\hline $\begin{array}{l}\text { Scientific name } \\
\text { (common name) }\end{array}$ & $\begin{array}{l}\text { Chr. number } \\
\text { and genome } \\
\text { size }\end{array}$ & Cultivar/accession/line & $\begin{array}{l}\text { Total } \\
\text { annotated } \\
\text { genes }\end{array}$ & $\begin{array}{c}\text { Reference and genome } \\
\text { database }\end{array}$ \\
\hline \multirow{3}{*}{$\begin{array}{l}\text { Cucumis sativus var. } \\
\text { sativus } \\
\text { (Cucumber) }\end{array}$} & \multirow[t]{3}{*}{$\begin{array}{c}2 \mathrm{n}=2 \mathrm{x}=14 \\
367 \mathrm{Mb}\end{array}$} & $\begin{array}{l}\text { Chinese cultivar } \\
\text { Chinese long Inbred line } 9930\end{array}$ & $\begin{array}{c}23,248 \\
\left(25,600^{\mathrm{z})}\right)\end{array}$ & $\begin{array}{l}\text { Huang et al. (2009) } \\
\text { http://cucurbitgenomics.org/ }\end{array}$ \\
\hline & & $\begin{array}{l}\text { North American cultivar } \\
\text { Gy14 gynoecious inbred line }\end{array}$ & 21,503 & $\begin{array}{l}\text { Cavagnaro et al. (2010) } \\
\text { https://phytozome.jgi.doe.gov/ }\end{array}$ \\
\hline & & $\begin{array}{l}\text { North-European cultivar } \\
\text { Borszczagowski line B10 }\end{array}$ & $\begin{array}{c}26,587 \\
\left(29,789^{\mathrm{y})}\right)\end{array}$ & $\begin{array}{l}\text { Wóycicki et al. (2011) } \\
\text { http://csgenome.sggw.pl/en-us/ }\end{array}$ \\
\hline $\begin{array}{l}\text { Cucumis sativus var. } \\
\text { hardwickii } \\
\text { (Wild cucumber) }\end{array}$ & Not available & Accession PI183967 & $\begin{array}{c}22,746 \\
\left(26,548^{\mathrm{z})}\right)\end{array}$ & $\begin{array}{l}\text { Qi et al. (2013) } \\
\text { http://cucurbitgenomics.org/ }\end{array}$ \\
\hline $\begin{array}{l}\text { Cucumis melo } \\
\text { (Melon) }\end{array}$ & $\begin{array}{c}2 \mathrm{n}=2 \mathrm{x}=24 \\
450 \mathrm{Mb}\end{array}$ & Double-haploid line DHL92 & $\begin{array}{c}27,432 \\
\left(34,848^{\mathrm{z})}\right) \\
\end{array}$ & $\begin{array}{l}\text { Garcia-Mas et al. (2012) } \\
\text { htttps://melonomics.net/ }\end{array}$ \\
\hline \multirow[t]{2}{*}{$\begin{array}{l}\text { Citrullus lanatus } \\
\text { (Watermelon) }\end{array}$} & \multirow[t]{2}{*}{$\begin{array}{c}2 \mathrm{n}=2 \mathrm{x}=22 \\
425 \mathrm{Mb}\end{array}$} & $\begin{array}{l}\text { East Asia watermelon cultivar } \\
97103\end{array}$ & 23,440 & $\begin{array}{l}\text { Guo et al. (2013) } \\
\text { http://cucurbitgenomics.org/ }\end{array}$ \\
\hline & & Cultivar Charleston Gray & 22,567 & http://cucurbitgenomics.org/ \\
\hline $\begin{array}{l}\text { Momordica charantia } \\
\text { (Bitter gourd) }\end{array}$ & $\begin{array}{c}2 \mathrm{n}=2 \mathrm{x}=22 \\
339 \mathrm{Mb}\end{array}$ & $\begin{array}{l}\text { A monoecious inbred line } \\
\text { OHB3-1 }\end{array}$ & $45,873^{\mathrm{x})}$ & Urasaki et al. (2016) \\
\hline Arabidopsis thaliana & $\begin{array}{c}2 \mathrm{n}=2 \mathrm{x}=10 \\
125 \mathrm{Mb}\end{array}$ & & $27,206^{\mathrm{w})}$ & $\begin{array}{l}\text { Arabidopsis Genome Initiative } \\
(2000) \\
\text { https://www.arabidopsis.org/ }\end{array}$ \\
\hline $\begin{array}{l}\text { Oryza sativa ssp. japonica } \\
\text { (Japonica rice) }\end{array}$ & $\begin{array}{c}2 \mathrm{n}=2 \mathrm{x}=24 \\
430 \mathrm{Mb}\end{array}$ & & 42,189 & $\begin{array}{l}\text { Ouyang et al. (2007) } \\
\text { https://phytozome.jgi.doe.gov/ }\end{array}$ \\
\hline
\end{tabular}

www.softberry.com/berry.phtml?topic=protcomppl\&group $=$ programs\&subgroup=proloc) with default parameters.

\section{Phylogenetic analysis of $\mathrm{DHN}$ genes}

The deduced protein sequences of $D H N$ genes were multiple aligned using MUSCLE included in MEGA 7 software (http://www.megasoftware.net/, Kumar et al. 2016) and then the phylogenetic tree was generated based on the alignments using the Maximum-Likelihood (ML) method by MEGA 7 software with the following parameters: Poisson model, pairwise gap deletion and 1,000 bootstraps. The deduced protein sequences of 10 and eight $D H N$ genes reported in $A$. thaliana (Hundertmark and Hincha 2008) and rice (Verma et al. 2017), respectively, were also included in the phylogenetic tree for comparison.

\section{In silico expression profiling of $\mathrm{DHN}$ genes in cucumber and melon}

The expression of $D H N$ genes in cucumber and melon was profiled using public RNA-Seq data [Bioproject accession no. PRJNA80169 (http://www.ncbi.nlm.nih. gov/bioproject/PRJNA80169, Li et al. 2011) for cucumber cv. Chinese long and PRJNA300582 (https://www.ncbi. nlm.nih.gov/bioproject/PRJNA300582, Kim et al. 2016) for melon (C. melo var. makuwa, oriental melon, Korean landrace KM)] deposited in GenBank SRA database. First, the RNA-Seq data were downloaded and trimmed using NGS OC Tool kit (v2.3.1). Trimmed RNA-Seq reads of high quality (Phred score $>20$ ) were mapped on proteincoding sequences (CDSs) predicted in the whole genome sequences, based on which Fragment Per Kilobase of transcript per Million mapped reads (FPKM) values were calculated using RSEM program with default parameters. 
Afterward, FPKM values for $D H N$ genes were chosen and used to draw heatmap using MeV s/w (Saeed et al. 2003) with default parameters.

\section{In silico analysis of $\mathrm{DHN}$ promoter sequences}

Putative promoter sequences of $2-\mathrm{kb}$ upstream from start codon of $D H N$ genes were retrieved from genome databases of cucumber, melon, and watermelon. Putative cis-acting elements in the sequences were investigated using PlantPAN 2.0 (http://plantpan2.itps.ncku.edu.tw/ promoter.php, Chow et al. 2016) and then elements related to abiotic stress response, such as dehydration response element (DRE, 5'-CCGAC-3' or 5'-CCGAA-3') and abscisic response element (ABRE, 5'-ACGCG-3' or 5'-ACGTG-3'), were selected. Afterward the elements with similar score of 1.0 (i.e. $100 \%$ identical to DRE and ABRE sequences) were further selected and used for generating a scheme showing distribution of cis-acting elements.

\section{RESULTS}

\section{$D H N$ genes and their features in five Cucurbitaceae species}

Genome-wide searches identified a total of 32 genes encoding DHNs in eight genome sequences of five Cucurbitaceae species (Table 2, Supplementary Table S1).
Among those, four, three, and four genes were identified in cucumber cv. Chinese long, cv. Gy14, and cv. Borszczagowski, respectively, and four in wild cucumber. In addition, four, five, four, and four genes were identified in melon, watermelon cv. 97103, cv. Charleston Gray, and bitter gourd, respectively (Table 2).

Among reported five protein architecture types of DHNs (Close 1996; Graether and Boddington 2014), three types, $\mathrm{K}_{\mathrm{n}}, \mathrm{SK}_{\mathrm{n}}$ and $\mathrm{Y}_{\mathrm{n}} \mathrm{SK}_{\mathrm{n}}$, were found in the deduced protein sequences of Cucurbitaceae $D H N$ genes whereas remaining two types, $K_{n} S$ and $Y_{n} K_{n}$, could not be found (Table 2). The $\mathrm{K}_{\mathrm{n}}, \mathrm{SK}_{\mathrm{n}}$ and $\mathrm{Y}_{\mathrm{n}} \mathrm{SK}_{\mathrm{n}}$-type DHNs were encoded by 6,15 and 11 Cucurbitaceae genes, respectively.

Subcellular location was predicted using three different tools such as PSORT, TargetP 1.1 and ProtComp 9.0. However, predicted subcellular locations of Cucurbitaceae DHNs were not consistent among the tools. All Cucurbitaceae DHNs were predicted to be located in nucleus by PSORT whereas some were predicted to be in cytoplasm or extracellular regions by ProtComp 9.0 (Supplementary Table S1). However, the predicted subcellular locations of Cucurbitaceae DHNs were similar to those of DHNs in $A$. thaliana and rice (Supplementary Table S2, S3).

Total $50 \mathrm{DHN}$ genes, including 32 Cucurbitaceae (in this study), 10 Arabidopsis (Hundertmark and Hincha 2008, Supplementary Table S2) and eight rice $D H N$ genes (Verma et al. 2017, Supplementary Table S3) could be divided into five groups in phylogenetic tree based on

Table 2. $D H N$ genes identified in this study.

\begin{tabular}{llcccccc}
\hline \hline \multirow{2}{*}{ Plant name } & \multirow{2}{*}{ Cultivar/accession/line } & Total $D H N$ & \multicolumn{5}{c}{ DHN YSK } \\
\cline { 3 - 7 } & genes & $\mathrm{K}_{\mathrm{n}}$ & $\mathrm{K}_{\mathrm{n}} \mathrm{S}$ & $\mathrm{SK}_{\mathrm{n}}$ & $\mathrm{Y}_{\mathrm{n}} \mathrm{K}_{\mathrm{n}}$ & $\mathrm{Y}_{\mathrm{n}} \mathrm{SK}_{\mathrm{n}}$ \\
\hline Cucumber & Chinese long & 4 & 1 & 0 & 2 & 0 & 1 \\
& Gy14 & 3 & 1 & 0 & 2 & 0 & 0 \\
\multirow{3}{*}{ Wild cucumber } & Borszczagowski & 4 & 1 & 0 & 2 & 0 & 1 \\
Melon & PI183967 & 4 & 1 & 0 & 2 & 0 & 1 \\
Watermelon & DHL92 & 4 & 1 & 0 & 2 & 0 & 1 \\
\multirow{3}{*}{ Bitter gourd } & Ch103 & 5 & 1 & 0 & 2 & 0 & 2 \\
Arabidopsis & OHB3-1 & 4 & 0 & 0 & 2 & 0 & 2 \\
Japonica rice & & 4 & 0 & 0 & 1 & 0 & 3 \\
\hline
\end{tabular}

${ }^{2)}$ Reported in Hundertmark and Hincha (2008) and Verma et al. (2017).

${ }^{\mathrm{y})}$ Identified in this study. 
similarity of amino acid sequences (Fig. 1). Although some DHN architecture types were grouped closely together with the same types, the whole grouping pattern seemed to be irrelevant to protein architecture of the used DHNs. Group I included all $\mathrm{SK}_{3}$-type DHNs in Cucurbitaceae, three $\mathrm{SK}_{2}$-type DHNs and a $\mathrm{SK}_{3}$-type DHN in A. thaliana, and a $\mathrm{SK}_{3}$-type DHN in rice. Group II included $\mathrm{K}_{6}$ and KS-type DHNs in A. thaliana and a KS-type DHN in rice. Group III included $\mathrm{Y}_{\mathrm{n}} \mathrm{SK}_{\mathrm{n}}$-type and YK-type DHNs. Group IV included mainly $\mathrm{SK}_{2}-, \mathrm{Y}_{\mathrm{n}} \mathrm{SK}_{\mathrm{n}}$ - and $\mathrm{YSK}_{\mathrm{n}}$-type DHNs.
Group V included mainly $\mathrm{SK}_{2}$ - and K-type DHNs. Group II and Group IV did not include DHNs identified in Cucurbitaceae, whereas Group V did not contain those in A. thaliana and rice. Among the five groups, in particular, Group I was comprised of DHNs involved in abiotic stress tolerance in Arabidopsis and rice, such as COR47, ERD10, and OsDHN1 (Hanin et al. 2011; Kumar et al. 2014), and also included eight DHNs (seven $\mathrm{SK}_{3}$ type and one $\mathrm{SK}_{2}$ type) identified in Cucurbitaceae species.

The Cucurbitaceae DHN genes showed $2 \%$ to $100 \%$

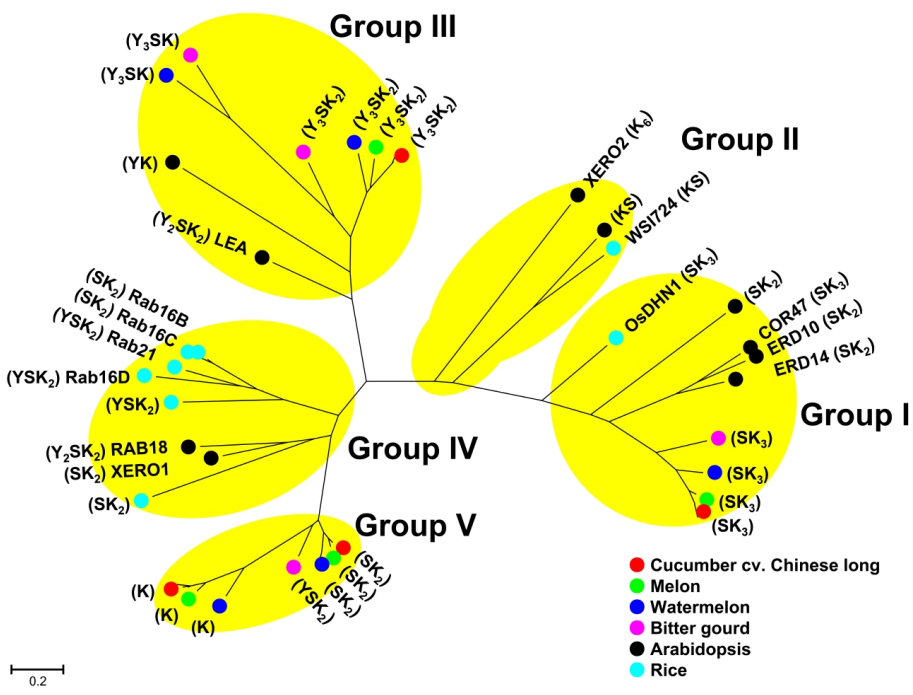

Fig. 1. Phylogenetic tree of $D H N$ genes identified in five Cucurbitaceae species. Tree was based on similarity among deduced protein sequences of $D H N$ genes identified in five Cucurbitaceae species, $A$. thaliana, and $O$. sativa. Five groups, Group I to V, were divided based on the proximity among genes at amino acid level. $D H N$ genes identified in cucumber cv. Chinese long and watermelon cv. 97103 were marked with red and blue circles, respectively, while ones in cucumber cv. Gy14, cv. Borszczagowski, wild cucumber and watermelon cv. Charleston Gray were not marked in the tree. Multiple sequence alignment of the protein sequences were performed using MUSCLE included in MEGA 7 software and then the phylogenetic tree was generated using the Maximum Likelihood (ML) method by MEGA 7 software. Scale bar represents the number of amino acid substitution per site. The bootstrap support values are omitted for a legible illustration. Group I consists of Csa6M358710.1, Cucsa.077690.1, gene_1\#CSB10A_v1_contig_6781, evm.model.Chr6.2030, MELO3C026550T1, Cla021949, ClCG08G009610.1, MOMC91_10, AT1G20440.1 (COR47), AT1G20450.1 (ERD10), AT1G76180.1 (ERD14), AT4G38410.1, and LOC_Os02g44870.1 (OsDHN1). Group II consists of AT1G54410.1, AT3G50970.1 (XERO2), and LOC_Os03g45280.1 (WSI724). Group III consists of Csa2M249810.1, Cucsa.109360.1 (partial CDS), gene_2\#CSB10A_v1_contig_3615, evm.model.Chr2.1250, MELO3C023323T1, Cla015906, Cla016586, ClCG02G004780.1, ClCG11G004140.1, MOMC39_188, MOMC7_421, AT4G39130.1, and AT2G21490.1 (LEA). Group IV consists of AT3G50980.1 (XERO1), AT5G66400.1 (RAB18), LOC_Os01g50700.1, LOC_Os11g26570.1, LOC_Os11g26750.1 (Rab16D), LOC_Os11g26760.1 (Rab16C), LOC_Os11g26780.1 (Rab16B), and LOC_Os11g26790.1 (Rab21). Group V consist of Csa4M045040.1, Csa4M045050.1, Cucsa.106380.1, evm.model.Chr4.526, evm.model.Chr4.527, gene_2\#CSB10A_v1_contig_5891, gene_3\#CSB10A_v1_contig_5891, MELO3C016401T1, MELO3C016402T1, Cla014570, Cla014571, ClCG07G008700.1, and MOMC8_239. Protein architecture types of $D H N$ genes indicated between parentheses. 
similarity to each other and $2 \%$ to $42 \%$ similarity to Arabidopsis and rice $D H N$ genes at amino acid level (Supplementary Table S4). Furthermore, the comparison of protein sequences revealed that K-segment was highly conserved in all DHNs in Cucurbitaceae species, $A$. thaliana, and rice. In addition, well conserved S- and Y-segments were also found in some DHNs (data not shown). For example, DHNs in Group I had highly conserved K- and S-segments (Fig. 2). In addition, whole protein sequences of DHNs in Cucurbitaceae species were

$\begin{aligned} & \text { Cucumber cv. Chinese long } \\ & \text { cv. Gy14 } \\ & \text { cv. Borszczagowski }\end{aligned}$
Wild cucumber
Melon clon
Watermelon cv. 97103
cv. Charleston Gray
Bitter gourd
Arabidopsis COR47
ERD10
ERD14
Arabidopsis
Rice OsDHN1
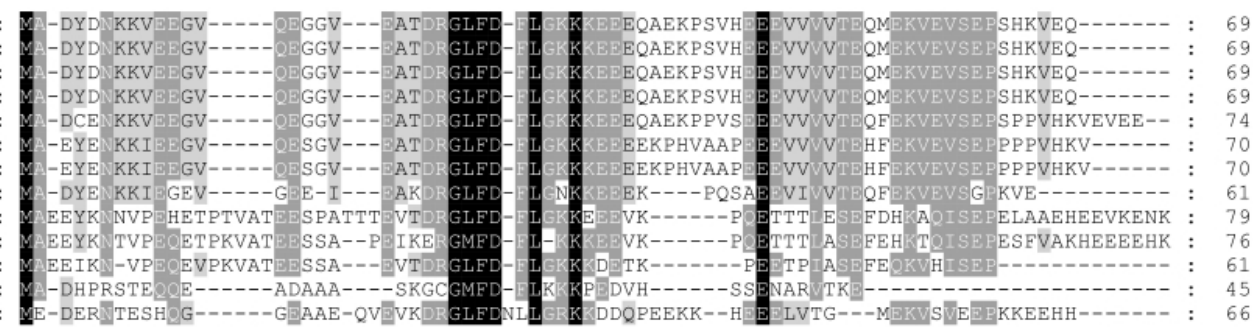

Cucumber cv. Chinese long
cv. Gy14
cv. Borszczagowski
Wild cucumber
Melon cv.
Watermelon cv. 97103
cv. Charleston Gray
Bitter gourd
Arabidopsis COR47
ERD10
Arabidopsis ERD14
Rice OsDHN1

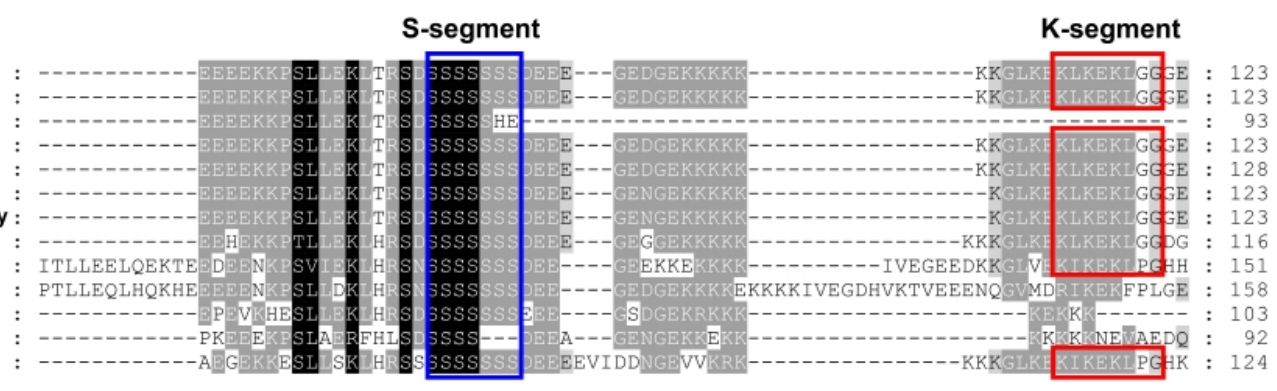

$\begin{aligned} & \text { Cucumber cv. Chinese long } \\ & \text { cv. Gy14 } \\ & \text { cv. Borszczagowski }\end{aligned}$
Wild cucumber
Melon cr.
Watermelon cv. 97103
cv. Charleston Gray
Bitter gourd
Arabidopsis COR47
ERD10
ERD14
Arabidopsis
Rice OsDHN1
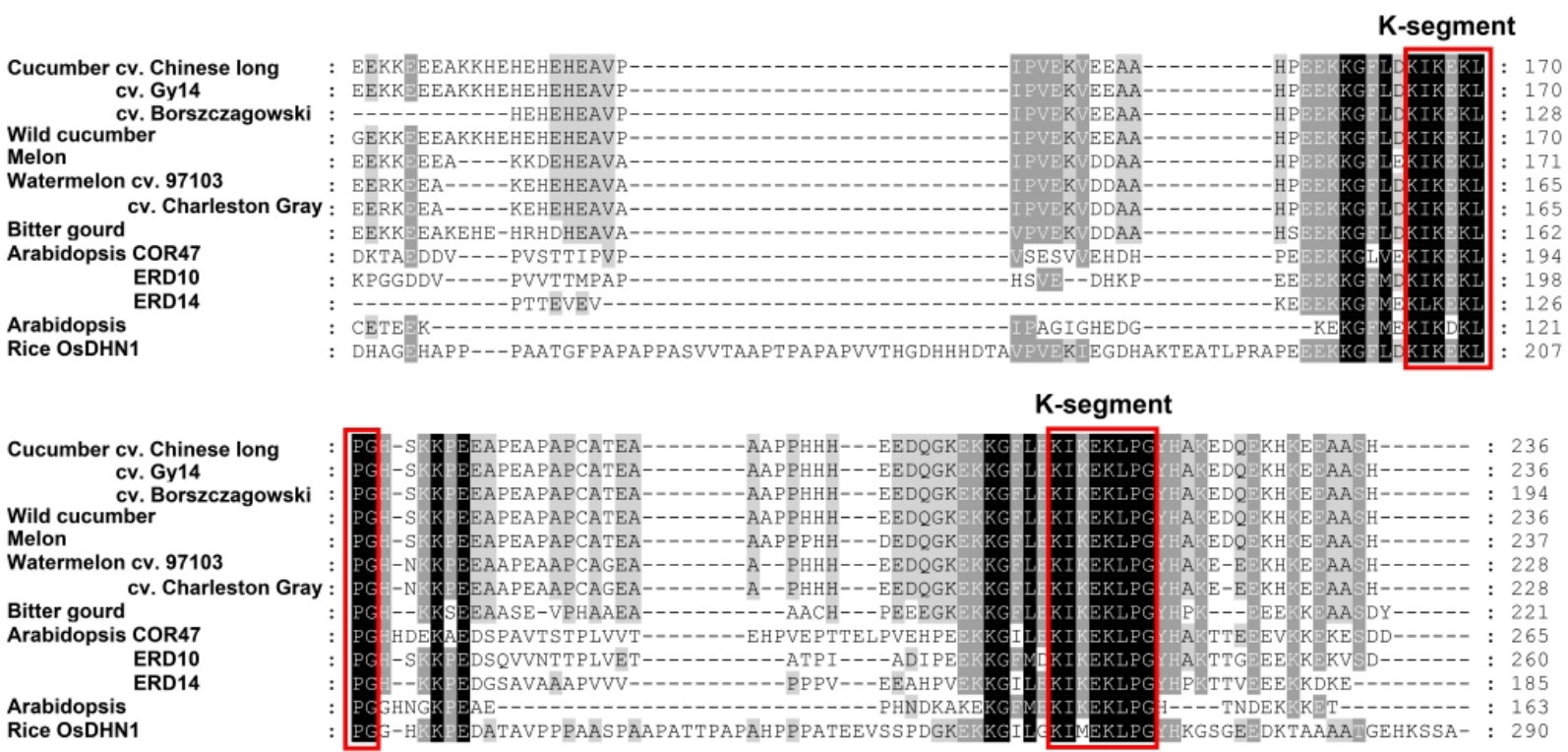

Fig. 2. Multiple alignment of the deduced protein sequences of $D H N$ genes in Group I. The conserved S- and K-segments are indicated by blue and red boxes, respectively. Shaded boxes indicate conserved residues among compared protein sequences. The alignment was made using MUSCLE in MEGA 7 program and visualized using GeneDoc software. Gene IDs of protein sequences used for multiple alignment are Csa6M358710.1 ( $\mathrm{SK}_{3}$, cv. Chinese long), ucsa.077690.1 (SK 3 , cv. Gy14), gene_1\#CSB10A_v1_contig_6781 (SK2, cv. Borszczagowski), evm.model.Chr6.2030 ( $\mathrm{SK}_{3}$, wild cucumber), MELO3C026550T1 ( $\mathrm{SK}_{3}$, melon), Cla021949 ( $\mathrm{SK}_{3}$, cv. 97103), ClCG08G009610.1 ( $\mathrm{SK}_{3}$, cv. Charleston Gray), MOMC91_10 ( $\mathrm{SK}_{3}$, bitter gourd), AT1G20440.1 ( $\mathrm{SK}_{3}$, COR47,RD17), AT1G20450.1 ( $\mathrm{SK}_{2}$, ERD10), AT1G76180.1 (SK 2 , ERD14), AT4G38410.1 (SK 2$)$, and LOC_Os02g44870.1 (SK $\left.3, \mathrm{OsDHN}_{1}\right)$. 
more similar to each other than to those in A. thaliana and rice, as expected.

\section{Expression profiles of $\mathrm{DHN}$ genes in cucumber and melon}

Public cucumber and melon RNA-Seq data were used for in silico expression profiling of $D H N$ genes in cucumber and melon, as mentioned in Materials and Methods. Among four cucumber $D H N$ genes, only $\mathrm{SK}_{3}$-type gene (Csa6M358710.1) showed strong expression in the ten examined tissues (leaf to ovary), whereas other three genes [Csa2M249810.1 ( $\left.\mathrm{Y}_{3} \mathrm{SK}_{2}\right)$, Csa4M045040.1 ( $\left.\mathrm{SK}_{2}\right)$, Csa4M045050.1 (K)] showed very low or no expression in the tissues (Fig. 3A, Supplementary Table S5). Similarly, only melon $\mathrm{SK}_{3}$-type $D H N$ gene (MELO3C026550T1) was strongly expressed in the five examined tissues among

(A)

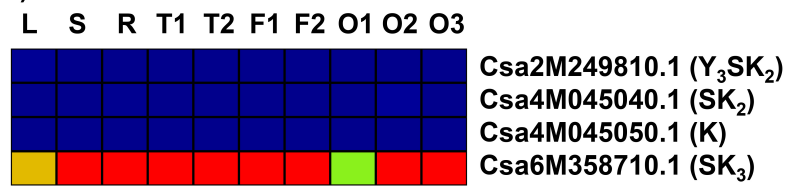

(B)

L S F1 F2 F3

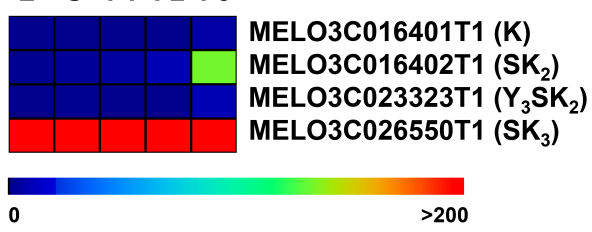

Fig. 3. Expression profiles of $D H N$ genes in cucumber and melon. Cucumber RNA-Seq data (Bioproject acc. PRJNA80169, Li et al. 2011) and melon RNA-Seq data (Bioproject acc. PRJNA300582, Kim et al. 2016) were retrieved from GenBank SRA database and employed to calculate FPKM values using RSEM program with default parameters (Supplementary Tables S5 and S6). FPKM values for $D H N$ genes of cucumber (A) and melon (B) were used to draw heatmap using $\mathrm{MeV} \mathrm{s} / \mathrm{w}$ with default parameters. Color scale for expression level (FPKM value) is shown at the bottom of heatmap. L, leaf; S, stem; R, root; T1, tendril base; T2, tendril; F1, female flower; F2, male flower; F3, fruit; O1, ovary; O2, expanded ovary without fertilization (7 days after flowering); O3, expanded ovary after fertilization (7 days after flowering). four melon $D H N$ genes (Fig. 3B, Supplementary Table S6). Melon $\mathrm{SK}_{2}$-type DHN gene (MELO3C016402T1) showed high expression only in fruit, which was slightly different from the expression profiles of cucumber $D H N$ genes.

\section{Cis-acting elements related to abiotic stress response in $\mathrm{DHN}$ promoter sequences}

Through in silico searching of cis-acting elements on putative promoter sequences of $D H N$ genes in cucumber (cv. Chinese long), melon (DHL92), and watermelon (97103), examined all 13 sequences were identified to contain DRE-like and/or ABRE-like sequences (Fig. 4). DRE and ABRE are well known as cis-acting elements for stress-induction of many stress responsive genes (Baker $e t$ al. 1994; Yamaguchi-Shinozaki and Shinozaki 1994; Jiang et al. 1996; Yamaguchi-Shinozaki and Shinozaki 2005). In particular, promoter sequences of $\mathrm{SK}_{3}$-type $D H N$ genes, Csa6M358710.1, MELO3C026550T1 and Cla021949, showed similar distribution of DRE- and ABRE-like sequences among cucumber, melon and watermelon.

\section{DISCUSSION}

Understanding the molecular mechanisms of abiotic stress responses in Cucurbitaceae crops is as important as in other crops to breed new cultivars with stress tolerance. On this account, $D H N$ genes encoding molecular chaperons were identified in Cucurbitaceae species through genomewide search. To the best of our knowledge, this study is the first to present the results of comprehensive analysis of $D H N$ genes in Cucurbitaceae species.

In this study, a total of $32 D H N$ genes were identified from eight genome sequences of five Cucurbitaceae species (Table 2). Each genome of the five species had three to five $D H N$ genes, which were almost identical to number of those genes reported previously in cucumber, melon and watermelon (Celik Altunoglu et al. 2016; Celik Altunoglu et al. 2017). On the other hand, $D H N$ gene number identified in each Cucurbitaceae genome was smaller than those in Arabidopsis and rice genomes. In addition, $\mathrm{K}_{\mathrm{n}} \mathrm{S}$ and $\mathrm{Y}_{\mathrm{n}} \mathrm{K}_{\mathrm{n}}$-type $D H N$ genes could not be found in Cucurbitaceae genomes, unlike Arabidopsis and rice. Although conserved 


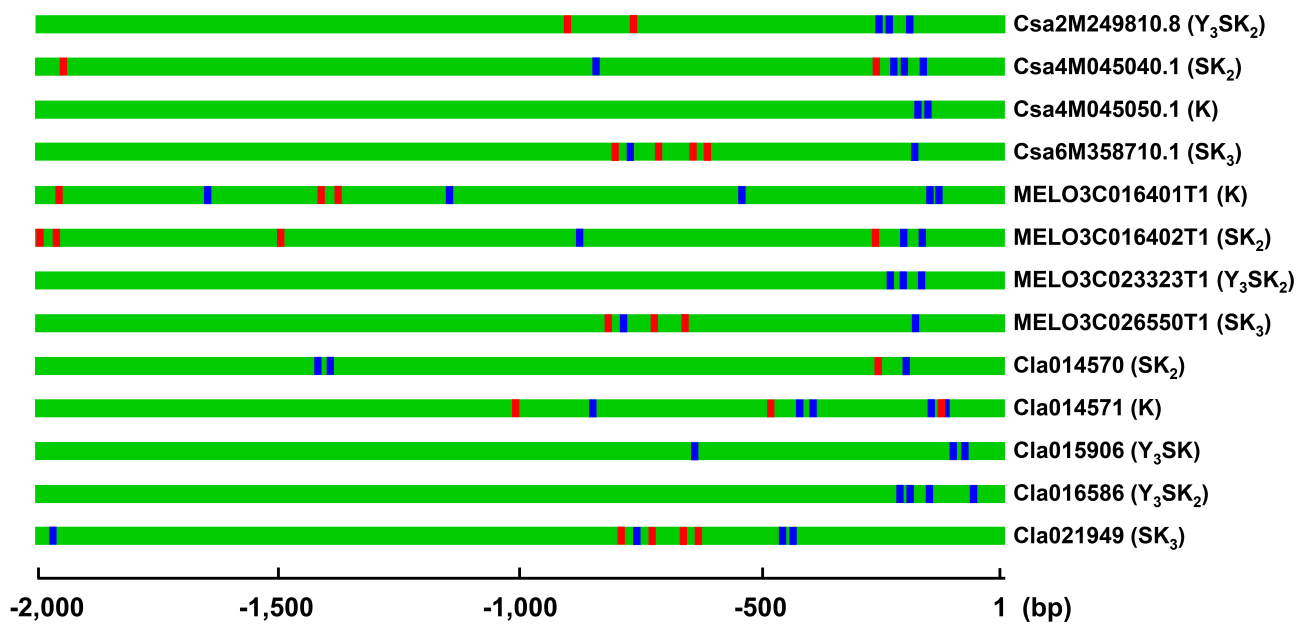

Fig. 4. Putative cis-acting elements related to abiotic stress response located in $D H N$ promoter sequences. Putative promoter sequences of 2-kb upstream from start codon were retrieved from genome databases of cucumber, melon, and watermelon and used to investigate putative cis-acting elements related to abiotic stress response using PlantPAN 2.0 (http://plantpan2.itps.ncku.edu.tw/promoter.php). Red and blue bars indicate DRE-like and ABRElike sequences. Gene IDs of cucumber (cv. Chinese long), melon, and watermelon DHN genes start with Csa, MELO, and Cla, respectively.

domain searches using reliable program and manual inspection were employed in this study, still it cannot be excluded that another $D H N$ gene with less conserved $\mathrm{K}$-segment might be present in Cucurbitaceae genomes. In fact, DHNs lacking complete K-segments were identified in Pinus pinaster (Perdiguero et al. 2014).

Although the detailed function of DHNs has not been known yet, several studies have revealed the function of DHNs (Rorat 2006). For example, some $\mathrm{YSK}_{\mathrm{n}}$-type DHNs bind to lipid vesicles, which are thought to contribute to maintaining membrane structure. $\mathrm{K}_{\mathrm{n}} \mathrm{S}$-type DHNs have the activity of reactive oxygen species (ROS) scavenging. $\mathrm{SK}_{\mathrm{n}}$ and $\mathrm{K}_{\mathrm{n}}$-type DHNs are closely related to cold acclimation (Rorat 2006). Therefore, considering the association of $\mathrm{SK}_{3}$-type $D H N$ genes to cold tolerance (Danyluk et al. 1994; Houde et al. 2004; Rorat 2006; Yin et al. 2006; Xing et al. 2011), Cucurbitaceae $\mathrm{SK}_{3}$-type DHNs in Group I might be important for cold tolerance (Fig. 1). This possibility can be supported by the Group I members, COR47 and OsDHN1, that are downstream target genes regulated by $\mathrm{CBF} / \mathrm{DREBs}$, key transcription factors for cold tolerance (Seki et al. 2001; Thomashow et al. 2001; Lee et al. 2005; Lee et al. 2013). In addition, Yin et al. (2006)'s study showed that overexpression of a Solanum sogarandinum $\mathrm{SK}_{3}$-type $D H N$ gene increase cold tolerance in transgenic cucumber seedling, which is also in accordance with our findings.

Among $D H N$ genes whose expressions were investigated, only $\mathrm{SK}_{3}$-type $D H N$ genes were strongly expressed in cucumber and melon (Fig. 3), although further analysis about expression change under stress condition is needed. In addition, DRE- and ABRE-like sequences were well conserved among promoter sequences of $\mathrm{SK}_{3}$-type $D H N$ genes in cucumber, melon, and watermelon (Fig. 4), which supports the role of the $\mathrm{SK}_{3}$-type DHNs in stress tolerance in Cucurbitaceae crops.

In conclusion, the present research characterized $D H N$ genes and their expression pattern in five Cucurbitaceae species through genome-wide searches and in silico expression profiling. The $D H N$ genes identified in this study will be valuable genetic resource for understanding stress response mechanism and assisting molecular breeding in Cucurbitaceae crops.

\section{ACKNOWLEDGEMENTS}

We thank Prof. Hideo Matsumura in Shinshu University, 
Japan for kindly providing gene set of bitter gourd. This work was supported by Korea Institute of Planning and Evaluation for Technology in Food, Agriculture, Forestry and Fisheries (IPET) through Agri-Bio industry Technology Development Program, funded by Ministry of Agriculture, Food and Rural Affairs (MAFRA) (grant numbers 116076-03-2-HD090 and 116076-03-2-HD0b0).

\section{REFERENCES}

Ali A, Bang SW, Yang EM, Chung SM, Staub JE. 2014a. Putative paternal factors controlling chilling tolerance in Korean market-type cucumber (Cucumis sativus L.). Scientia Horticulturae 167: 145-148.

Ali A, Yang EM, Bang SW, Chung SM, Staub JE. 2014b. Assessment of chilling injury and molecular marker analysis in cucumber cultivars (Cucumis sativus L.). Kor. J. Hort. Sci. Technol. 32: 227-234.

Arabidopsis Genome Initiative. 2000. Analysis of the genome sequence of the flowering plant Arabidopsis thaliana. Nature 408: 796-815.

Baker SS, Wilhelm KS, Thomashow MF. 1994. The 5'-region of Arabidopsis thaliana cor15a has cis-acting elements that confer cold-, drought- and ABA-regulated gene expression. Plant Mol. Biol. 24: 701-713.

Bravo LA, Gallardo J, Navarrete A, Olave N, Martínez J, Alberdi M, et al. 2003. Cryoprotective activity of a cold induced dehydrin purified from barley. Physiol. Plant. 118: 262-269.

Brini F, Hanin M, Lumbreras V, Amara I, Khoudi H, Hassairi A, et al. 2007. Overexpression of wheat dehydrin $\mathrm{DHN}-5$ enhances tolerance to salt and osmotic stress in Arabidopsis thaliana. Plant Cell Rep. 26: 2017-2026.

Cavagnaro PF, Senalik DA, Yang L, Simon PW, Harkins TT, Kodira CD, et al. 2010. Genome-wide characterization of simple sequence repeats in cucumber (Cucumis sativus L.). BMC Genomics 11: 569.

Celik Altunoglu Y, Baloglu MC, Baloglu P, Yer EN, Kara S. 2017. Genome-wide identification and comparative expression analysis of $L E A$ genes in watermelon and melon genomes. Physiol. Mol. Biol. Plants 23: 5-21.

Celik Altunoglu Y, Baloglu P, Yer EN, Pekol S, Baloglu MC. 2016. Identification and expression analysis of $L E A$ gene family members in cucumber genome. Plant Growth
Regul. 80: 225-241.

Chow CN, Zheng HQ, Wu NY, Chien CH, Huang HD, Lee TY, et al. 2016. PlantPAN 2.0: an update of plant promoter analysis navigator for reconstructing transcriptional regulatory networks in plants. Nucleic Acids Res. 44(D1): D1154-D1160.

Close TJ. 1996. Dehydrins:emergence of a biochemical role of a family of plant dehydration proteins. Physiol. Plant 97: 795-803.

Danyluk J, Houde M, Rassart É, Sarhan F. 1994. Differential expression of a gene encoding an acidic dehydrin in chilling sensitive and freezing tolerance gramineae species. FEBS Lett. 344: 20-24.

Danyluk J, Perron A, Houde M, Limin A, Fowler B, Benhamou N, et al. 1998. Accumulation of an acidic dehydrin in the vicinity of the plasma membrane during cold acclimation of wheat. Plant Cell 10: 623-638.

Garcia-Mas J, Benjak A, Sanseverino W, Bourgeois M, Mir G, González VM, et al. 2012. The genome of melon (Cucumis melo L.). Proc. Natl. Acad. Sci. U.S.A. 109: 11872-11877.

Graether SP, Boddington KF. 2014. Disorder and function: a review of the dehydrin protein family. Front Plant Sci. 5: 576.

Guo S, Zhang J, Sun H, Salse J, Lucas WJ, Zhang H, et al. 2013. The draft genome of watermelon (Citrullus lanatus) and resequencing of 20 diverse accessions. Nat. Genet. 45: 51-58.

Hanin M, Brini F, Ebel C, Toda Y, Takeda S, Masmoudi K. 2011. Plant dehydrins and stress tolerance: versatile proteins for complex mechanisms. Plant Signal Behav. 6: 1503-1509.

Hara M. 2010. The multifunctionality of dehydrins: An overview, Plant Signal Behav. 5: 503-508.

Hara M, Terashima S, Fukaya T, Kuboi T. 2003. Enhancement of cold tolerance and inhibition of lipid peroxidation by citrus dehydrin in transgenic tobacco. Planta 217: 290-298.

Houde M, Dallaire S, N'Dong D, Sarhan F. 2004. Overexpression of the acidic dehydrin WCOR410 improves freezing tolerance in transgenic strawberry leaves. Plant Biotechnol. J. 2: 381-387.

Huang S, Li R, Zhang Z, Li L, Gu X, Fan W, et al. 2009. The genome of the cucumber, Cucumis sativus L. Nat. Genet. 41: 1275-1281. 
Hundertmark M, Hincha DK. 2008. LEA (late embryogenesis abundant) proteins and their encoding genes in Arabidopsis thaliana. BMC Genomics 9: 118.

Jiang C, Iu B, Singh J. 1996. Requirement of a CCGAC cis-acting element for cold induction of the BN115 gene from winter Brassica napus. Plant Mol. Biol. 30: 679684.

Jones P, Binns D, Chang HY, Fraser M, Li W, McAnulla C, et al. 2014. InterProScan 5: genome-scale protein function classification. Bioinformatics 30: 1236-1240.

Kim HA, Shin AY, Lee MS, Lee HJ, Lee HR, Ahn J, et al. 2016. De novo transcriptome analysis of Cucumis melo L. var. makuwa. Mol. Cells 39: 141-148.

Kumar M, Lee SC, Kim JY, Kim SJ, Aye SS, Kim SR. 2014. Over-expression of dehydrin gene, OsDhn1, improves drought and salt stress tolerance through scavenging of reactive oxygen species in rice (Oryza sativa L.). J. Plant Biol. 57: 383-393.

Kumar S, Stecher G, Tamura K. 2016. MEGA7: Molecular evolutionary genetics analysis version 7.0 for bigger datasets. Mol. Biol. Evol. 33: 1870-1874.

Kusano T, Aguan K, Abe M, Sugawara K. 1992. Nucleotide sequence of a rice rabl6 homologue gene. Plant Mol. Biol. 18: 127-129.

Lee SC, Kim SH, Kim SR. 2013. Drought inducible OsDhn1 promoter is activated by OsDREB1A and OsDREB1D. J. Plant Biol. 56: 115-121.

Lee SC, Lee MY, Kim SJ, Jun SH, An G, Kim SR. 2005. Characterization of a stress-inducible dehydrin gene, OsDhn1, from rice (Oryza sativa L.). Mol. Cells 19: 212-218.

Li Z, Zhang Z, Yan P, Huang S, Fei Z, Lin K. 2011. RNA-Seq improves annotation of protein-coding genes in the cucumber genome. BMC Genomics 12: 540.

Lu A, Jeffrey C. 2011. Cucurbitaceae (http://www.efloras.org/ florataxon.aspx?flora_id=2\&taxon_id=10233). In: ZY. Wu, PH. Raven, DY. Hong (eds.). Flora of China. Vol. 19. Science Press, Beijing, and Missouri Botanical Garden Press, St. Louis.

Nylander M, Svensson J, Palva ET, Welin BV. 2001. Stress-induced accumulation and tissue-specific localization of dehydrins in Arabidopsis thaliana. Plant Mol. Biol. 45: 263-279.

Ouyang S, Zhu W, Hamilton J, Lin H, Campbell M, Childs K, et al. 2007. The TIGR Rice Genome Annotation Re- source: improvements and new features. Nucleic Acids Res. 35(Database issue): D883-D887.

Perdiguero P, Collada C, Soto A. 2014. Novel dehydrins lacking complete K-segments in Pinaceae. The exception rather than the rule. Front Plant Sci. 5: 682.

Qi J, Liu X, Shen D, Miao H, Xie B, Li X, et al. 2013. A genomic variation map provides insights into the genetic basis of cucumber domestication and diversity. Nat. Genet. 45: 1510-1515.

Rorat T. 2006. Plant dehydrins: tissue location, structure and function. Cell. Mol. Biol. Lett. 11: 536-556.

Rural Development administration (RDA). 2013. Cucumber cultivation-Agricultural technique guide 107. RDA. Korea

Saeed AI, Sharov V, White J, Li J, Liang W, Bhagabati N, et al. 2003. TM4: a free, open-source system for microarray data management and analysis. Biotechniques 34: 374-378.

Seki M, Narusaka M, Abe H, Kasuga M, YamaguchiShinozaki K, Carninci P, et al. 2001. Monitoring the expression pattern of 1300 Arabidopsis genes under drought and cold stresses by using a full-length cDNA microarray. Plant Cell 13: 61-72.

Thomashow MF, Gilmour SJ, Stockinger EJ, Jaglo-Ottosen KR, Zarka DG. 2001. Role of the Arabidopsis CBF transcriptional activators in cold acclimation. Physiol. Plant. 112: 171-175.

Urasaki N, Takagi H, Natsume S, Uemura A, Taniai N, Miyagi N, et al. 2016. Draft genome sequence of bitter gourd (Momordica charantia), a vegetable and medicinal plant in tropical and subtropical regions. DNA Res. 24: 51-58.

Verma G, Dhar YV, Srivastava D, Kidwai M, Chauhan PS, Bag SK, et al. 2017. Genome-wide analysis of rice dehydrin gene family: Its evolutionary conservedness and expression pattern in response to PEG induced dehydration stress. PLoS ONE 12: e0176399.

Welin BV, Olson A, Palva ET. 1995. Structure and organization of two closely related low-temperatureinduced dhn/lea/rab-like genes in Arabidopsis thaliana L. Heynh. Plant Mol. Biol. 29: 391-395.

Wóycicki R, Witkowicz J, Gawroński P, Dąbrowska J, Lomsadze A, Pawełkowicz M, et al. 2011. The genome sequence of the North-European cucumber (Cucumis sativus L.) unravels evolutionary adaptation mechanisms 
in plants. PLoS ONE 6: e22728.

Wu S, Shamimuzzaman M, Sun H, Salse J, Sui X, Wilder A, et al. 2017. The bottle gourd genome provides insights into Cucurbitaceae evolution and facilitates mapping of a Papaya ringspot virus resistance locus. Plant J. doi: 10.1111/tpj.13722.

Xing X, Liu Y, Kong X, Liu Y, Li D. 2011. Overexpression of a maize dehydrin gene, $Z m D H N 2 b$, in tobacco enhances tolerance to low temperature. Plant Growth Regul. 65: 109-118.

Yamaguchi-Shinozaki K, Shinozaki K. 1994. A novel cisacting element in an Arabidopsis gene is involved in responsiveness to drought, low-temperature, or high-salt stress. Plant Cell 6: 251-264.

Yamaguchi-Shinozaki K, Shinozaki K. 2005. Organization of cis-acting regulatory elements in osmotic- and coldstress-responsive promoters. Trends Plant Sci. 10: 88-94.

Yin Z, Rorat T, Szabala BM, Ziółkowska A, Malepszy S. 2006. Expression of a Solanum sogarandinum $\mathrm{SK}_{3}$-type dehydrin enhances cold tolerance in transgenic cucumber seedlings. Plant Sci. 170: 1164-1172.

Zolotarov Y, Strömvik M. 2015. De novo regulatory motif discovery identifies significant motifs in promoters of five classes of plant dehydrin genes. PLoS ONE 10: e0129016. 